\title{
TQM Metrics in Mobile Applications Industry
}

\author{
Ahlam Al-Harbi ${ }^{1}$, Maram Baatya ${ }^{2}$, Azrilah Abdaziz ${ }^{3}$ \\ Department of Information Systems, Computing and Information Technology College, King Abdulaziz University, \\ Jeddah, Kingdom of Saudi Arabia ${ }^{1,2}$ \\ $\mathrm{PhD}$, Department of Information Systems, Faculty of Computing and Information Technology, King Abdulaziz \\ University, Jeddah, Kingdom of Saudi Arabia ${ }^{3}$
}

\begin{abstract}
Development of mobile applications is a young market and open broadly to organizations and individuals for competition. Software organizations utilize total quality management (TQM) strategies progressively to enhance their operations and procedures as a part of every single zone of their business. This study focuses on the Total Quality Management (TQM) properties in mobile applications industry. It aims to explore the relation between mobile application development and TQM. It identifies the metrics and attributes that help to gain successful implementation of TQM tools in field of mobile applications platform. The importance of this paper comes from the significance knowledge which provides an experience of implementing TQM in field of mobile applications industry with an overview of mobile applications. It concludes with clarifying benefits of applying TQM strategies, and how TQM philosophy could be conducted successfully.
\end{abstract}

Keywords: TQM, quality, mobile applications, information systems.

\section{INTRODUCTION}

Almost every organization has at least one information system to collect, organize, store and manipulate data for better decision making. Whenever the information system is good, the decision-making process will be better. Unfortunately, existence of an information system in an organization is not enough, there must be a certain level to accept effectiveness and efficiency. So, quality of any software projects plays an important role in its success. There are various ways to measure quality of information systems. All these ways depend on many factors such as; type of the information system, what it is used for and where it is used.

This paper will discuss information systems on mobile platform. Mobile devices became handy everywhere. They are distinguished easy to use, portable and capabilities of performing many tasks and missions with less efforts. Mobile applications (abbreviated with "mobile app") are characterized by special properties which make them as a special type of information systems. In addition, assessment quality of mobile applications is also different. This process has to be done by experts in developing of mobile applications, specialists in quality with business owners of course, to specific prioritization of metrics. Managing quality of mobile applications process is affected by the type of devices; screentouch devices have many characteristics different from which are in button-clicks devices[1]. A number of studies have examined some concepts of quality of mobile applications in healthy especial to measure how these applications are validated and reliable.

The goal of our paper is to clarify what are the most important TQM metrics and to understand how they are applied to mobile applications industry. Total quality has turned out to be famous and well-known in all fields it could serve. It endeavours to enhance, manage and promote quality, profitability, and intensity by enhancing connections with users, supplies providers and inside organization itself. Quality metrics in mobile applications industry are strongly depends on the purpose of an application, for example; medical applications should be at high level of validated and graphic applications should be at appropriate resolution. This paper introduces usability, customer satisfaction and response time as the most important metrics in mobile applications industry.

This paper is divided into sections to explain the TQM implementation in mobile platforms. These sections are organized as follow: section 2 is about mobile devices and their characteristics and industry of applications. Section 3 presents total quality management concepts and principles and how could apply to mobile applications industry. Section 4 presents how software organizations apply TQM concepts in mobile applications industry. Finally, section 5 concludes the paper.

\section{OVERVIEW OF MOBILE APPLICATION}

\section{A. Mobile Applications Development Process}

Mobile applications can be classified according to three main types [2]: 


\section{IARJSET

1. Native Mobile Applications

Native or genuine mobile applications fabricated by utilizing mobile phone SDKs suppliers, for example, given by Apple (iOS) also by Samsung (Android). Mobile applications that said to be native are paired executable items that everyone can download and execute specifically on the gadget of a smart mobile phone. Native mobile applications could likewise be introduced by an IT section on an end client mobile phone device. Native mobile applications have guide access to genuine components of the mobile phone. These genuine components may incorporate such things as the camera, GPS and ... etc. and also can work in off-line.

\section{Mobile Web Applications}

Mobile web applications are not really applications but we can call it mobile web innovation. It has developed from web scratching in the beginning of mobile in which firms would essentially gathered some of information focuses from their corporate site and convey them as the portable or mobile web applications or site (hosted by third-party). Today's mobile phones especially smart ones and tablets generally have full support in browsing the website. Likewise, it is easy to build a mobile web applications not linked to a corporate site and fabricated for portability. Mobile web application is considered to have a comparative common feature to a native applicationand is constructed totally with web innovative techniques, for example, HTML:

- Mobile JavaScript Frameworks

- HTML5

\section{Hybrid Mobile Applications}

Hybrid mobile applications contain some combined features from native mobile applications and web applications. These Hybrid mobile applications have two essential components:

- Web techniques such as HTML and JavaScript

- Native gateway or bridge that allow mobile application to get into genuine device components as: cameraaccelerometer, etc.

\section{B. Mobile Applications Development Process}

New digital and electronic technologies are used in various ways in our daily lives. Nowadays, mobile technology with smartphones and tablets open new visions and they are parts of the growing trends in communications, commerce and education. Mobile technologies provide many advantages for users such as; flexibility, interactivity and localization. Mobile applications industry has recently taken good attention and more improvements. As shown in Error! Reference source not found.[3], [4], at the last years, the increasing of mobile users and applications hasn't been a problem because they already are increasing [5]. Growing numbers of mobile applications in the marketplace has challenged developers to build superior quality to compete. And the basic question now is: how the users act with the applications and what they prefer.

As shown as any software system, mobile applications developing process is divided into many stages; gathering requirements, analysis, design, implementation and testing. Each stage has its challenges and properties. And there are many aspects of mobile applications which we should pay careful attention from the beginning of developing process, such as; collecting data and analysis are done by an analytic, application icons and user interfaces are designed by an UI designer and secure is made by a secure specialist.

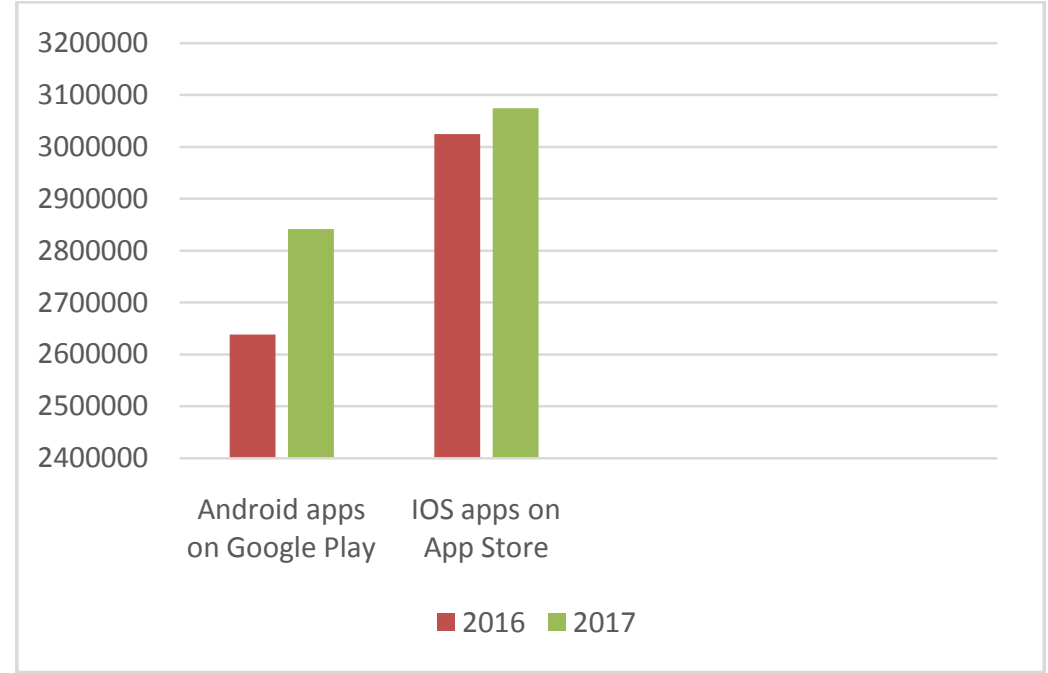

Fig.1 number of mobile applications on different Marketplaces 


\section{IARJSET

The process of developing mobile applicationrequires high quality of resources, tools and technologies with good plans to avoid high costs and risks of repetitive correction steps [1]. Mobile applicationdevelopment process starts with specifying group members and the platform the app will be used on. Developing a mobile application according to the platform is necessary to build high degree of reliability, consistency and fast performance application. In addition, that facilitates choosing tools used to design and implementation such as SDK, gives easy access to mobile hardware such as camera and geolocation[6].

\section{Mobile Applications Characteristics and Particularities}

Mobile devices differ from computers and other electronics devices. They have many characteristics and particularities in hardware and software. Mobile devices are limited in memory, CPU speed and power supply[6].

All mobile applications should work everywhere and anytime with no need to prior training, but with need to rapid repair to error-free state, ensured high security and the ability for automatic updates. The characteristics and particularities of mobile applications that affect the development process are [7]:

Startup-time: for an application is an essential feature but at the same time is a complicated and delicate task and the consequences of startup times of different applications design frameworks are often not clear. However, it is an important matter for users since they tend to utilize their mobilephone as a basic tool of communication. So, to know more about what happens during the time between when an application starts launching and when the primary functions have the control and how that time is related to application code and components. The ability to speed this startup process becomes a basic issue for all users.

Responsiveness: A mobile device looks like a little mechanical apparatus that is suitable for your quick communication needs, and users expect that it is an essential tool for them. When user try to click or tap its applications, click a button, or do physical action to it, there must be a physical response. If users did not have a quick response, they will be unsatisfied. A mobile application to be responsiveness it must accomplish some knowledge for the user, and this function have some aspects one of these aspects is to complete the requested action by application users. The other aspect is that the application receives the request and starts to process it while the user is waiting. The unwanted aspect for a mobile application is leaving the users without complete knowledge about their request or action being processed or not, being accepted or not. So, mobile application must be responsive as the user expect.

Focused purpose: mobile application must have obvious, focused and characterized sets; it must do them with a base number of touches, clicks, or other client actions; and it must do them rapidly. This is an honourable objective however ought not to be done at client profitability. Invest the energy to compose the additional code to ensure that application has a certain function and empowers clients to accomplish their objectives as fast as could be expected.

Customized Interactions with Off-Device Information Sources: Understanding that building an extraordinary mobile application is not simply an issue of getting the code that keeps running correctly on the device. It should on the other hand think to have the off-line device program that mobile application communicates with. Data sources that provide service to mobile phones ought to be given suitable thought in the free application's design to guarantee that they are returning data in a way that is compatible for mobile phones.

Consistency of Experience: Since mobile phones are smaller and independent, user actually sees the entire device as a understanding experience. Every mobile phone has its particular configuration. Commonly, good mobile applications don't show up to such an extent as discrete application yet rather as normal component augmentations of the mobile phone's experience.

\section{III.TOTAL QUALITY MANAGEMENT FOR MOBILE APPLICATIONS}

\section{A. Overview of TQM}

Total quality management contains of globalized firm efforts and a coordinated system standards, strategies, and good practices to introduce and make a long-lasting environment in which an association consistently enhances its capacity to produce brilliant product of high quality and service to clients. TQM is also defined as total profitable issue that describes a management methodology to long-lasting positively satisfied client. Through Total quality management procedures, all individuals of a company play a role in enhancing and develop production steps, items, service, and the way of life they work in [8].

Generally, TQM approach has various principles[9]that can be applied for any industry. First of all, focusing and paying more attention on users' need. Also, doing things right from the first time and trying to improve in it. Effective communication open a window between managers and employees. They should always measure and report the work by using specific tools and charts. Finally, all levels of managers and employees with users should be involve for creating good and organized work environment.

TQM approach has many basics concepts [9]that we can apply for any industry. The TQM approach is a customerdriven and a long-term committed management process. In TQM approach, all team members work with others as partners and use whole available resources and capabilities effectively. That will lead to measure performance frequently and continuous improvements. 


\section{IARJSET

There are some barriers and obstacles with implementation of TQM, that can be overcame with good planning, such as; incompatible organizational structure and isolated employees and departments, ineffective measurement techniques, paying inadequate attention to internal and external customers, failure to continually improve and inadequate use of empowerment and teamwork.

\section{B. History of TQM}

A historical development of TQM can be traced over four periods: inspection, statistical quality control, quality assurance and strategic quality management.

At the beginning of year 1800, the improvement of inspection gear was an essential moment in the science of quality control. F. Taylor review (inspection exercises by performing a simple duty to the operative foreman worker to be one of his 8 duties for successful company managing in the mid of $1900 \mathrm{~s}$. With the publication of quality control procedures by G. Radford during 1922, quality control became a separate management responsibility and function. A statistical mechanism for controlling of products attributes in 1922 was the initial start of Statistical Quality Control. In that duration, statistic approve sampling replaced full inspection was developed [10].

Quality control initially started as manual-based and now many evaluations and measurement process are done by computer-based applications. Using technology in implementing TQM helps in complex calculations, analyse data, writing reports and decisions making.

TQM has an overall view of quality. It takes many dimensions in many directions [9]. It involves all levels of work powers behaviour, production processes, strategic planning and work environments.

\section{TQM Metrics for Mobile Applications and Cost of Poor Quality}

Determining and understating quality metrics of mobile applications industry is important to increase public awareness and competition for building high quality applications [11]. Metrics of TQM for mobile applicationsare a matter of debate but the benefits of implementation TQM methods are unlimited. This section will discuss applying the concepts and principles of TQM mentioned in the previous section in mobile applications industry.

There are some issues in mobile applicationsdeveloping. Among challenging issues in mobile applicationsdeveloping is that about being portable. Another issue is deficiency of being stable in web-applicationsseems to be a serious problem. Beside an increase issue on applications developing is successful computation. Time and performance are critical metrics of quality and availability of additional user options is another metric of quality [12]. In (P.Pocatilu, 2015) [1] the researchers have mentioned TQM for mobile applications characterized by many different dimensions;

- User: development driven by specific needs and demands of users (user contribution), minimal efforts for using, high performance.

- Developer: individual or group, their professional, systematic approaches to improve the abilities and experience of team members,

- Organization management; effective using of resources and costs, open culture, permanent concern of the whole organization to provide the latest improved tools and technologies and specific member to monitor the implementation of TQM during the developing mobile applications.

- Developing process: focus on the qualitative but not quantitative side of the app, the coverage of all stages of the application lifecycle and especially user experience, maintenance, and reengineering.

Mobile charger's efficient became an essential requirement claimed by mobile applications. Applications maintenance and modification ability is an issue as mobile applications have typically a fast update cycle. The primary goal is to modify to user requirements needs a frequent software development. This problem increase as multi-platform needs support and maintain ability and modification ability is an essential issue, since the cost is related to how many platforms is supported [13]. Quality is playing an important role when compare between mobile applications. Poor quality applications are a result of low commitment and applying TQM methods at the different dimensions. There is high cost with poor quality mobile applications. Because one negative experience a customer has with an application, it would cost much about efforts, money and reputation. Investments more efforts to avoiding poor mobile applications costs in two lanes: appraisal and prevention. Appraisal costs are about locating how conform properties of the application with quality requirements such as performance. Prevention costs are about minimizing the failure and appraisal costs such as costs to explore and fix bugs. But what about poor quality applications? Are they died? The answer is that we can repair and enhance the quality of applications, and that is very necessary, by increase appraisal and prevention efforts with failure costs [14].

\section{Evaluation of TQM in Mobile Applications}

Quality of mobile applicationscannot be measured only by free-faults; it must be broader, including characteristics to cover all aspects, development process phases and viewpoints. Mobile apps are evaluation from three different points of view [1]: 
1. The organization (investor): who seeks to minimize the costs, risks and maximize the material and moral profits.

2. The developer:who aims to build an effective and efficient product in a reasonable time and resources.

3. The user: who aims to achieve his/her objective with minimal efforts and time.

Fig. is shown the dimensions and directions of TQM in mobile applicationsindustry.

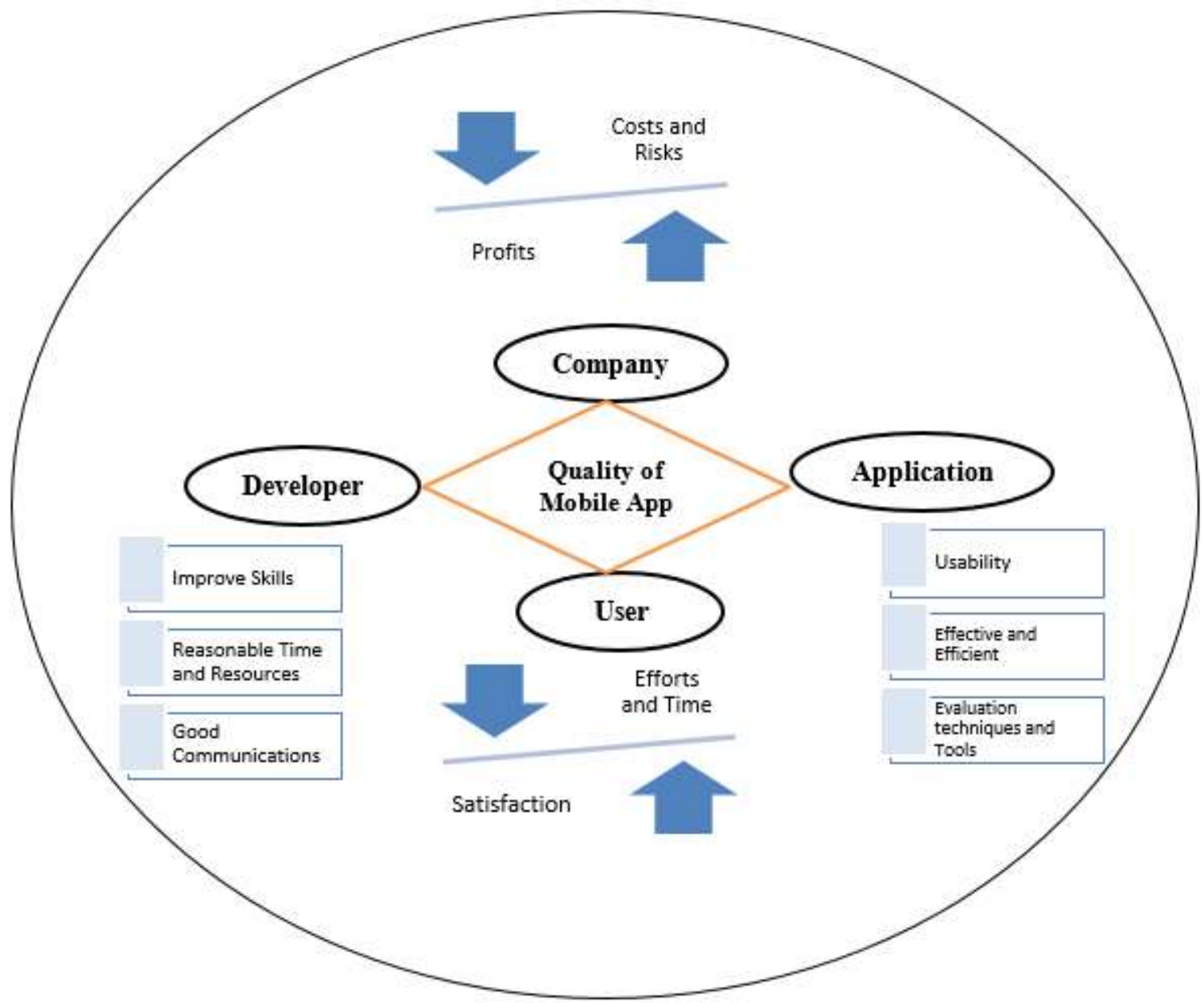

Fig.2 TQM Environment for Mobile Applications Industry

There are many tools and techniques to satisfy quality criteria of mobile applicationssuch as; users rating on the applicationsmarketplaces, Mobile App Rating Scale MARS that used for mobile healthy applicationsand checklists[15]. An Aggregate Indicator IA used in (P.Pocatilu, 2015) [1] is a statistical measure to assess the quality of mobile applications, between $0-1$, depending on 10 metrics to identify causes of low quality and enhance.

There are several systems to define quality values and issues of mobile applications. The standards that are based on quality or explaining quality issues consist of some main metrics, to evaluate the applications [13].

1) Usability:

There are many aspects to the quality of mobile applications, an important one is usability. Usability has a very important role in mobile applications. Some of usability mobile applicationsaspects are: ease of use, interface design, learnability, data entry methods, frequency of use, existing of shortcuts, familiar in vocabulary and flow of information [1]. Not all applications that need you to pay for to download are helpful or good quality [11].

Until recent years, mobile applications have been evaluated subjectively with no specific process. Now researchers develop some methodology used to analyse and measure aspects of usability. Some of these methodologies most often used by researchers are [16]:

- Lab experiments; people contribution in controlled setting.

- field studies; asking users about their experience. 


\section{IARJSET

It is preferred that users contribute with development team at early stage in application developing process and take their suggestions and opinions, that leads to better content and designing with high quality and usability [10].

- $\quad$ hands-on measurement; measure aspects of applicationsto evaluate usability.

Every one of these evaluation methods has its advantages and disadvantages, some are difficult and others depend on opinions[16].

The purpose of a mobile applicationsplays an important role for defining metrics of usability. So, the developer should take into account the purpose of the application as a first step to define its usability.

2) Customer Satisfaction:

Consumers must be satisfied and their purchasing decisions need to be influenced. So, vendor and manufacturer must follow the steps leading to their customer[13].It will be a good practice to know their needs and prefers to provide at high level of quality. That should be a chance to develop the apps and achieve differentiation and get the users satisfaction. Users usually are attracted to validated useful contents applications, valid content that is evidence-based is an important aspect of evaluation the quality of health care and education apps [11].

3) Response time:

Performance defined as capability of systems to respond to their activity orders, that is, the time required to transfer a responsive action to an issue or number of issues processed in an exact timing unit. Response time is a remarkable value to which a framework can finish its tasks within an exact period. Performance of any mobile applicationsrelies on the duration of a single duty, responsive period of a process, accurate results, being reliable, being available, errortolerance, storage volume and being scalable [13].

\section{IV.CONCLUSION}

TQM is not only a philosophy but also a rule for employees. It has enhanced many firms' performance to develop the quality of product and operations, and maximize the profitability. Any mobile applications or software company planning to apply the total quality management must own the essential number of its workers following quality management philosophy and methods before proceeding to the core market. When an organization decide to apply TQM as a working model, that means there will be a totally change at the organization culture and environment which in some cases not easy. Everyone related to the value chain of the mobile application market, like; developer and user, are significant and should play his or her own role well, otherwise, the chain will be broken, and the TQM process will soon fall apart. In other words, the number of people involved in TQM implementation would most likely determine the chance of TQM success[17].

\section{REFERENCES}

[1] P.Pocatilu, I.Ivan, A.Zamfiroiu and C.Boja, "An aggregate indicator for mobile application quality assessment,"Turkish Journal of Electrical Engineering \& Computer Sciences, pp. 956 - 973, June. 2013.

[2] Clouds, S., Dark Linings, A., Reed, A., \& Bennett, S. G. Mobile Strategy, "How Your Company Can Win by Embracing Mobile Technologies," 288 pages, Dirk Nicol, IBM Press, 2013.

[3]Number of Android applications,AppBrain, 2017.[Online]. Available: http://www.appbrain.com/stats/number-of-android-apps. [Accessed 7 March 2017].

[4]App Store Metrics,pocketgamer,2017. [Online]. Available: http://www.pocketgamer.biz/metrics/app-store/app-count/. [Accessed 2 Mar 2017].

[5]D. Chaffey. (2017) "Mobile Marketing Statistics compilation," Smart insights.[Online].Available:http://www.smartinsights.com/mobilemarketing/mobile-marketing-analytics/mobile-marketing-statistics/. [Accessed 74 2017].

[6] M.E. Joorabchi, A. Mesbah and P. Kruchten "Real challenges in mobile app development," in Empirical Software Engineering and Measurement, 2013 ACM/IEEE International Symposium on, 2013, pp.15-24.

[7] N. Dirk,Mobile strategy: How your company can win by embracing mobile technologies,Pearson Education, 2013

[8] D. Kiran, "Total Quality Management," Butterworth-Heinemann, 2016.

[9] NVR Naidu, KM Babu and G Rajendra, Total Quality Management, New Delhi, India.

[10]H. Kaynak,Total quality management and just-in-time purchasing: Their effects on performance of firms operating in the US, Taylor \& Francis, 1997.

[11] C. Reynoldson, C. Stones, M. Allsop, P. Gardner,M.I. Bennett, J.Closs, R. Jones and P. Knapp, "Assessing the Quality and Usability of Smartphone Apps for Pain Self-Management," Pain Medicine, vol.15, pp. 898-909, 2014

[12] S.A. Alamri and A.AbdulAziz, "The Effectiveness of Implementing Total Quality Management in Software Development,"IARJSET, vol.3, pp. 206-211, June 2016.

[13]R. Cruz and A. Miguel,“Modern Software Engineering Methodologies for Mobile and Cloud Environments,”IGI Global, 2016.

[14] R. Coowar, "Quality Control", [PowerPoint slides] Retrieved from Lecture Notes.

[15]S.R. Stoyanov, L. Hides, D.J. Kavanagh, O. Zelenko, D. Tjondronegoro and M. Mani, "Mobile app rating scale: a new tool for assessing the quality of health mobile apps," JMIR mHealth and uHealth, vol 3, pp. e27, 2015.

[16]F. Nayebi, J-M. Desharnais and A.Abran, " The state of the art of mobile application usability evaluation," Electrical \& Computer Engineering (CCECE), 2012 25th IEEE Canadian Conference on,2012, pp. 104

[17]E. Y. Li, H. Chen, W. Cheung,"Total Quality Management in Software Development Process,"The Journal of Quality Assurance Institute,2000, p. $4-6 \& 35-41$ 